\title{
Antibodies to Saccharomyces cerevisiae in patients with Crohn's disease and their possible pathogenic importance
}

\author{
M H Giaffer, A Clark, C D Holdsworth
}

\begin{abstract}
Saccharomyces cerevisiae (baker's yeast) may play an important part in the pathogenesis of Crohn's disease. Because of this the levels of IgG and IgA antibodies against three $S$ cerevisiae strains (NCYC 77, NCYC 79, and NCYC 1108) were assayed in 49 patients with Crohn's disease, 43 with ulcerative colitis, 14 with coeliac disease, and 21 healthy controls. Coded serum samples were tested by ELISA. Similar antibody patterns to all three strains were found. IgG and IgA antibody levels were significantly raised in patients with Crohn's disease compared with healthy controls $(\mathrm{p}<0.001$ and $\mathrm{p}<0.0001$ respectively) and with ulcerative colitis patients $(\mathbf{p}<0.0001$ and p $<0.0006$ respectively). Raised IgA, but not IgG, yeast antibody levels were found in two patients with Crohn's disease who were intolerant to yeast, but these values were similar to those in other patients without yeast intolerance. In ulcerative colitis, both IgG and IgA levels were similar to normal controls. Patients with small bowel Crohn's disease had significantly higher IgG antibody levels than those with colonic disease $(p<0 \cdot 01)$. High levels of IgG, but not IgA, antibody were present in patients with coeliac disease, the antibody responses being indistinguishable from those found in Crohn's disease. It is concluded that the presence of IgG antibody to $S$ cerevisiae is characteristic but not specific to Crohn's disease. Although raised IgA antibody levels are more frequently found in Crohn's disease, their pathogenic importance remains to be established.
\end{abstract}

(Gut 1992; 33: 1071-1075)

There is no firm epidemiological or experimental evidence that directly links diet and Crohn's disease, although the results of dietary surveys' and the as yet unconfirmed therapeutic value of 'exclusion diets' ${ }^{23}$ suggest that dietary factors may precipitate or perpetuate acute exacerbations in some patients with this disorder.

A local intestinal immune response to as yet unidentified antigen(s) resulting in tissue damage and granuloma formation has been suggested as a possible mechanism of tissue injury in Crohn's disease. ${ }^{4}$ Both dietary and bacterial antigens have been implicated. Thus circulating antibodies to various dietary and bacterial antigens have been described in patients with inflammatory bowel disease ${ }^{5-9}$ as well as in coeliac disease. ${ }^{10} \mathrm{~A}$ recent report suggested that milk may be an 'aetiologic factor' in a patient with Crohn's ileitis." Main et $a l^{12}$ showed that $\operatorname{IgG}$ and $\operatorname{IgA}$ antibodies to
Saccharomyces cerevisiae (baker's yeast) are present in high titres in patients with Crohn's disease but not in those with ulcerative colitis or normal control subjects. Thus, they claimed that yeasts may be aetiologically relevant in some patients with Crohn's disease.

In view of the unconfirmed pathological importance of yeast antibodies in Crohn's disease, this study was designed to examine the prevalence and possible pathogenic significance of IgG and IgA antibodies specific to $S$ cerevisiae in patients with Crohn's disease and ulcerative colitis using patients with coeliac disease and healthy subjects as controls.

\section{Patients and methods}

\section{PATIENTS}

Forty nine patients with Crohn's disease were studied. There were 21 men and 28 women with a mean age of 45 years (range 19-77). The diagnosis was based on established clinical, radiological, and histological criteria as previously described. ${ }^{13}$ In 14 patients the disease was confined to the large bowel; the remaining 35 had radiological evidence of small bowel disease with or without colonic involvement. The disease was considered clinically active in 18 patients and quiescent in the remaining 31 . The disease was considered active if the Crohn's disease activity index ${ }^{14}$ was greater than 150 and the value of at least one laboratory investigation (such as the erythrocyte sedimentation rate, $\mathrm{C}$ reactive protein, $\alpha_{1}$ acid glycoprotein, platelet count, haemoglobin, and serum albumin) was abnormal. ${ }^{15}$

Forty three patients had ulcerative colitis -18 men and 25 women with a mean age of 47 years (range 22-81). Eighteen of these had active disease, confirmed sigmoidoscopically and by histology, and the remaining 25 had quiescent disease.

None of the patients with inflammatory bowel disease was receiving steroids or other immunosuppressive drugs at the time of the study. Most patients with Crohn's colitis and all those with ulcerative colitis were taking sulphasalazine or other 5-amino salicylic acid releasing preparations.

The control groups included 20 healthy volunteers (eight men, 12 women with a mean age of 34 years (range 19-48)) and 14 patients with established coeliac disease. In the latter group, 11 were taking gluten free diet; the other three had newly diagnosed disease and were on a normal unrestricted diet. 
IMMUNOLOGICAL METHODS

A $10 \mathrm{ml}$ blood sample was collected from each patient. This was allowed to clot at room temperature, centrifuged, and the serum was separated into a sterile container. The sample was coded and stored at $-20^{\circ} \mathrm{C}$ for later testing. Serial serum samples before and after treatment with the elemental diet (Vivonex) were obtained from four patients with clinically active Crohn's disease.

The enzyme linked immunosorbent assay (ELISA) was applied to quantitate the specific IgG and IgA antibody responses to the yeast $S$ cerevisiae.

\section{Antigen preparation}

Three $S$ cerevisiae strains were used to prepare yeast antigens. These included NCYC 77 and NCYC 79 (baker's yeast) and NCYC 1108 (brewer's yeast). The strains were kindly provided by Dr H McKenzie, University of Aberdeen, UK. The yeasts were cultured on separate Sabouraud agar slopes (Oxoid Ltd, Basingstoke, Hampshire) for 48 hours at $37^{\circ} \mathrm{C}$. The growth was harvested and washed twice before being resuspended in $0 \cdot 15 \mathrm{M}$ sterile saline so that a 1:10 dilution had an optical density of 0.25 at $540 \mathrm{~nm}$. The suspension was then boiled for 60 minutes and stored at $4^{\circ} \mathrm{C}$. A 1:10 dilution of the boiled antigen suspension in $0.05 \mathrm{M}$ carbonate bicarbonate buffer ( $\mathrm{pH} 9.6$ ) was used to coat the wells of the microtitre plates.

\section{Antibody assay}

Flat bottomed microtitre plates ( 96 wells) (Alpha Laboratories Ltd, UK) were coated with $100 \mu \mathrm{l}$ of antigen suspension per well and incubated at $37^{\circ} \mathrm{C}$ for 60 minutes and at $4^{\circ} \mathrm{C}$ for 16 hours. Each well was then washed four times with $0.05 \mathrm{M}$ phosphate buffered saline, $\mathrm{pH} 7 \cdot 3$, to which $0.01 \%(\mathrm{v} / \mathrm{v})$ Triton X-100 was added (PBS-T). Test sera were diluted 1:100 using PBS-T to which $1 \%(\mathrm{w})$ bovine serum albumin was added (PBS-T-BSA). Each serum sample was tested in duplicate. A $100 \mu \mathrm{l}$ aliquot of serum was added to each antigen coated well. In addition to test sera, each plate included a positive and a negative reference serum and a negative control where no serum was added. The plates were then incubated at $37^{\circ} \mathrm{C}$ for 60 minutes and washed four times with PBS-T. A $100 \mu \mathrm{l}$ aliquot of affinity purified alkaline phosphatase conjugated antihuman IgG or IgA (Sigma, Poole, Dorset) diluted 1:400 in PBS-T-BSA was added to each well and the incubation and washing steps were repeated. One hundred $\mu \mathrm{l}$ of a $2 \mathrm{mg} / \mathrm{ml}$ solution of P-nitrophenyl phosphate (Sigma) in $0.05 \mathrm{M}$ glycine-sodium hydroxide buffer $\mathrm{pH} 10 \cdot 2$, were then added to each well. The plates were incubated at $37^{\circ} \mathrm{C}$ for $30-40$ minutes until the optical density of the positive reference serum reached the predetermined value of 1.0 at $410 \mathrm{~nm}$, at which time the optical densities of the test sera were read (Microelisa Minireader MR590, Guernsey, Channel Islands, UK). Thus the quantities of IgG and IgA anti-yeast antibodies were expressed as optical density measurements in relation to the reference positive serum.
STATISTICAL ANALYSIS

Data were expressed as mean (SEM). The MannWhitney $U$ test was used to examine the significances in the differences in antibody levels between study groups. Intercorrelation between IgG and IgA antibodies to various $S$ cerevisiae strains were tested using Spearman's equation.

\section{Results}

Figure 1 (A, B, and C) shows the distribution of IgG and IgA levels against baking (NCYC 77 and NCYC 79) and brewing (NCYC 1108) $S$ cerevisiae strains in all study groups.

In Crohn's disease, IgG values against NCYC 77, NCYC 79, and NCYC 1108 strains were significantly higher than those of healthy controls $(\mathrm{p}<0.001, \mathrm{p}<0.01$, and $\mathrm{p}<0.001$ respectively) and ulcerative colitis patients $(\mathrm{p}<0.0002$, $\mathrm{p}<0.001$, and $\mathrm{p}<0.005$ respectively). IgA titres were generally present at lower serum concentrations than IgG. But like IgG, IgA titres against all three yeast strains were significantly raised in patients with Crohn's disease compared with those with ulcerative colitis and normal controls (Figs 1A, B, and C). Patients with ulcerative colitis, regardless of disease activity, had IgG and IgA antibody values that were not significantly different from those found in healthy controls.

Figures 2 and 3 show that the site of Crohn's disease influenced the antibody titres. Patients with small bowel involvement had significantly higher IgG antibody titres against NCYC 77 and NCYC 1108 than those with colonic disease, whether or not the small bowel was also affected $(\mathrm{p}<0.01$ and $\mathrm{p}<0.004$ respectively). Although there was a difference between small and large bowel disease in IgA antibody values, this difference was not statistically significant. Other factors such as age, sex, disease activity, or previous intestinal resection had no effect on the antibody titres (data not shown). Twenty patients with Crohn's disease were tested for individual food intolerances, ${ }^{15}{ }^{16}$ and three identified yeast as a possible trigger food. Two of these had raised IgA but not IgG titres, although the antibody values were similar to those found in subjects without yeast intolerance. The third declined testing.

Serial measurements of IgG and IgA were made in four patients before and four weeks after treatment with an elemental diet. ${ }^{15}$ This treatment had no effect on the IgG or IgA titres.

Raised IgG or IgA values against one $S$ cerevisiae strain correlate well with $\operatorname{IgG}$ or $\operatorname{IgA}$ values against the other two strains (Table). Of the 26 patients with Crohn's disease who had raised IgG against NCYC 77 strain, 24 (92\%) and $21(81 \%)$ also had raised IgG against NCYC 79 and NCYC 1108 respectively. In the same group, $20(77 \%), 20(77 \%)$, and $18(69 \%)$ also had increased IgA levels against NCYC 77, NCYC 79 , and NCYC 1108 respectively.

In patients with coeliac disease, IgG but not IgA values against all three $S$ cerevisiae strains were significantly raised compared with those in ulcerative colitis and normal controls. The raised IgG antibody concentrations in these patients were comparable with those seen in Crohn's disease; high IgG concentrations were equally 

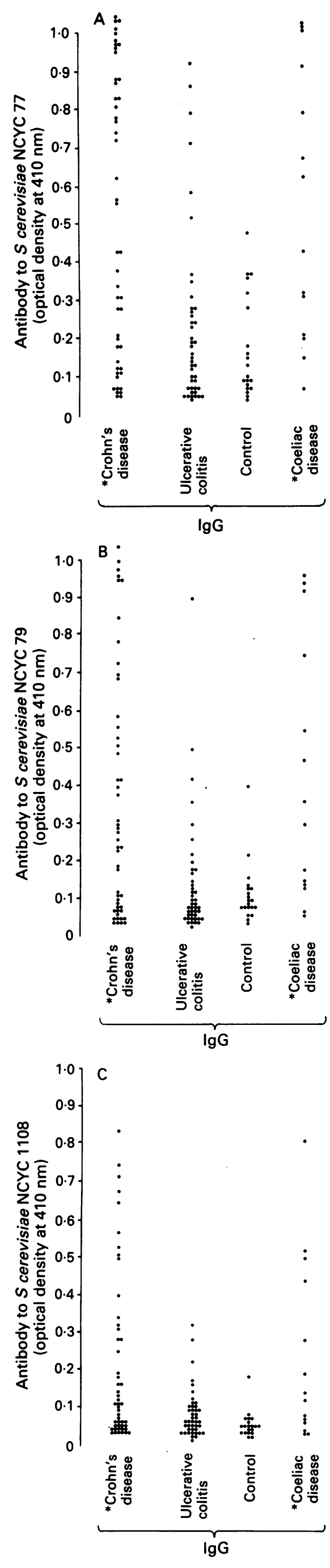

present in treated and untreated patients with coeliac disease. In contrast, the mean IgA antibody titres in coeliac disease were similar to those in normal controls and patients with ulcerative colitis (Figs 1A, B, and C). Increased IgA antibody values were therefore found mainly in patients with Crohn's disease.

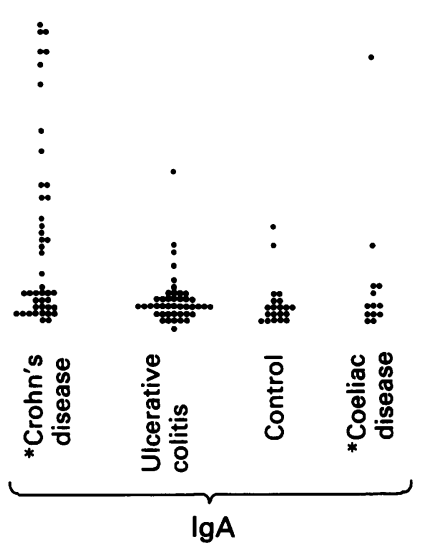

\section{Discussion}

In this study, patients with established Crohn's disease had significantly raised IgG and IgA values against baking and brewing yeasts $(S$ cerevisiae). In contrast, the ulcerative colitis patients had antibody values comparable with healthy controls. This confirms previous observations ${ }^{12} 17$ which also showed that the patients with Crohn's disease tended to have high levels of IgG and IgA anti-yeast antibodies. In marked contrast to these authors, however, we found that the raised IgG levels against $S$ cerevisiae depended upon disease site. Patients with confirmed small bowel involvement, whether or not the large bowel was also affected, had higher IgG levels than those in whom the disease was confined to the colon. Apart from anatomical location, no other patient or disease factor influenced the acquisition of high IgG antibody levels. The presence of raised IgG levels against all three $S$ cerevisiae strains in coeliac disease raises questions about the importance of this antibody in Crohn's disease which was claimed by previous workers. ${ }^{12} 17$

In agreement with a recent report, ${ }^{18} \operatorname{IgA}$ antibody against $S$ cerevisiae was more specific to Crohn's disease, for significantly higher levels were found only in this condition. Coeliac disease patients and those with ulcerative colitis generally had IgA levels that were not different from healthy controls. Furthermore, raised IgA levels in Crohn's disease were equally found in patients with small and large bowel disease. Thus, the raised IgA levels could not be accounted for on the basis of disease site. Even so its pathogenic significance is not certain for the presence of yeast antibodies did not correlate with a previous history of yeast intolerance. Two of our patients who had documented intolerance to yeast had IgG and IgA antibody levels that were not different from those of other patients without such a history. It could be argued that IgG antibody is usually of higher affinity than IgA and might mask an IgA response, but, if this was the case this would merely increase the significance of the raised IgA levels reported here. It is accepted that serum IgA responses must be interpreted as a reflection of the mucosal secretory IgA response which could not be evaluated in this study.

It is possible that the raised IgG titres against $S$ cerevisiae reflect enhanced intestinal permeability. The higher levels of IgG antibodies found in our patients with small bowel Crohn's disease are consistent with this hypothesis. A mucosal permeability defect has been shown 


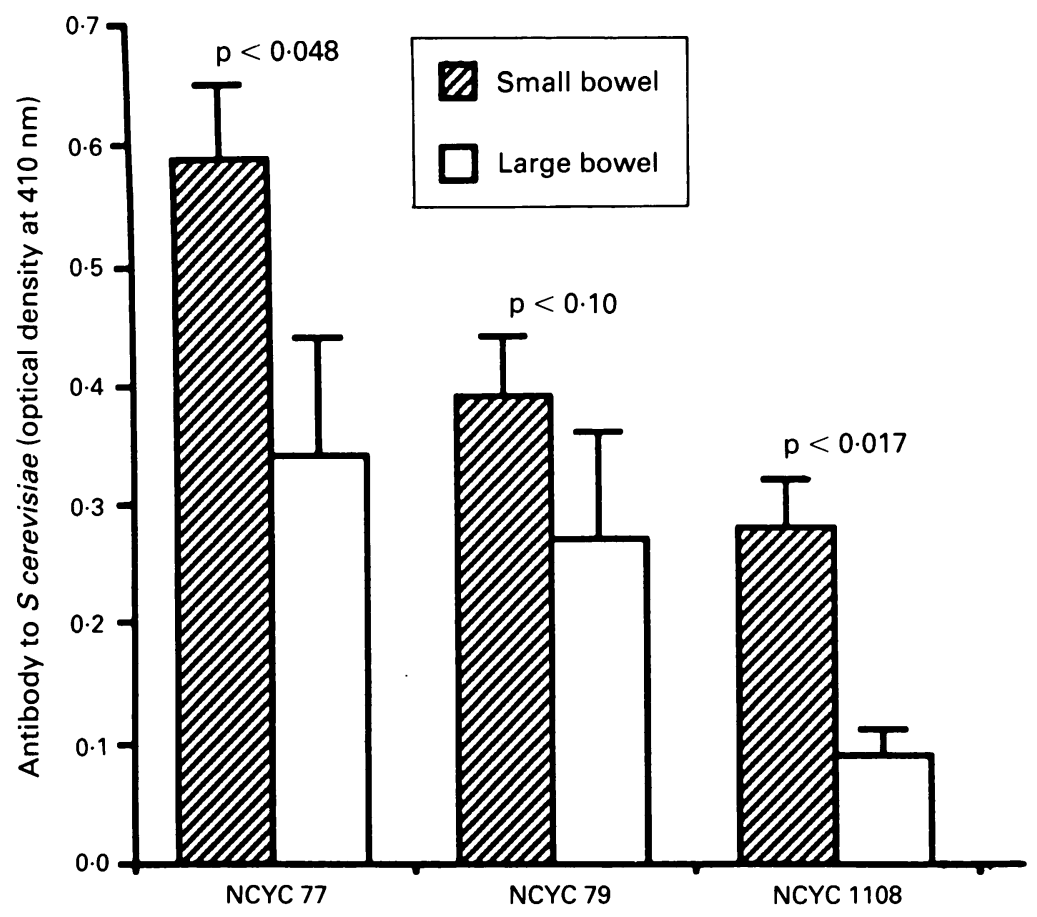

Figure 2: Effect of disease site on the mean (SEM) serum IgG antibody levels (expressed as optical density at $410 \mathrm{~nm}$ ) in Crohn's disease.

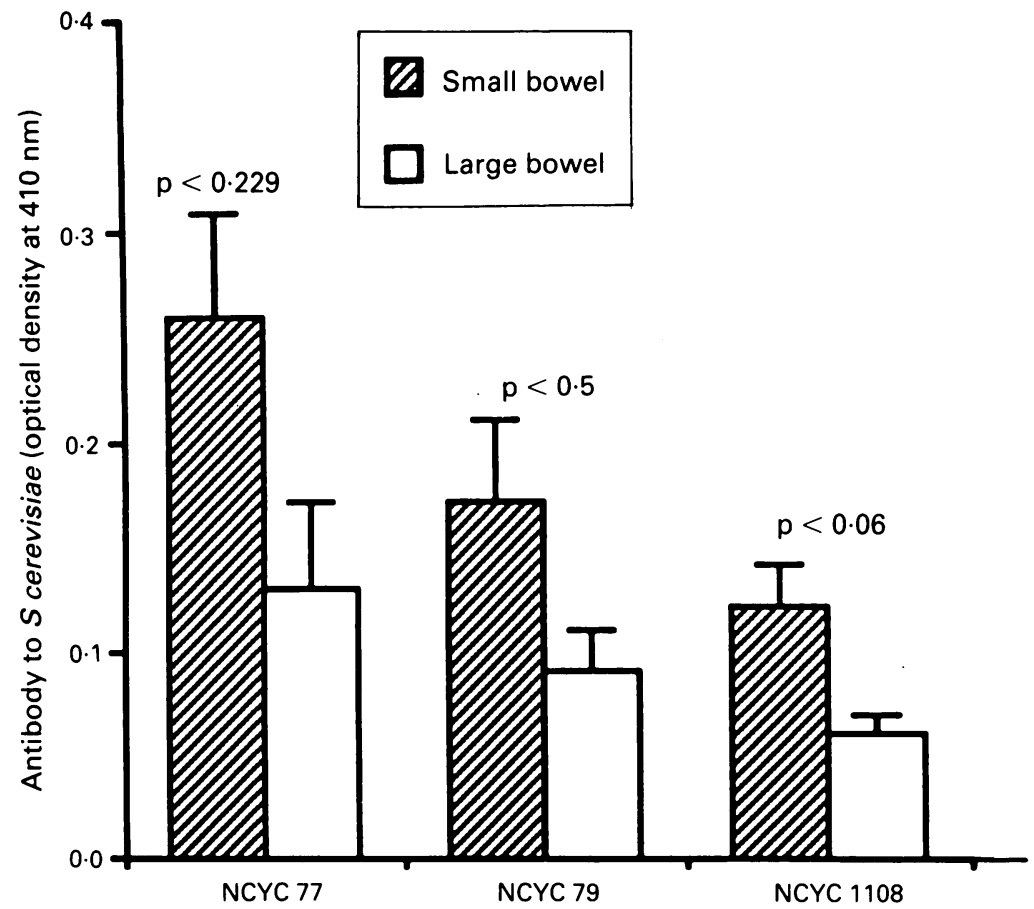

Figure 3: Effect of disease site on the mean (SEM) serum IgA antibody levels (expressed as optical density at $410 \mathrm{~nm}$ ) in Crohn's disease.

Spearman's correlation matrix of IgG and IgA against all three Saccharomyces cerevisiae strains NCYC 77, NCYC 79, and NCYC 1108

\begin{tabular}{llllll}
\hline $\begin{array}{l}\text { Antibody/ } \\
\text { yeast strain }\end{array}$ & $\begin{array}{l}\text { IgG/ } \\
\text { NCYC 77 }\end{array}$ & $\begin{array}{l}\text { IgG/ } \\
\text { NCYC 79 }\end{array}$ & $\begin{array}{l}\text { IgG/ } \\
\text { NCYC 1108 }\end{array}$ & NCYC 77 & NGA/ \\
\hline IgG/NCYC 79 & 0.839 & & & & \\
IgG/NCYC 1 108 & 0.794 & 0.734 & & & \\
IgA/NCYC 77 & 0.732 & 0.660 & 0.754 & & \\
IgA/NCYC 79 & 0.669 & 0.671 & 0.70 & 0.961 & \\
IgA/NCYC 1108 & 0.567 & 0.543 & 0.680 & 0.878 & 0.830 \\
\hline
\end{tabular}

All correlations were significant at $\mathrm{p} \leq 0.0001$. in patients with Crohn's disease and their relatives, ${ }^{19}$ as well as in those with coeliac disease. ${ }^{20}$ The abnormally permeable mucosa may permit the transfer of larger quantities of luminal antigens across the intestinal wall. This antigenic load may then initiate an immune response resulting in increased levels of circulating antibodies against the antigens. This concept is supported by the fact that patients with Crohn's disease have high antibody titres against a wide variety of dietary antigens to which the patient is usually not clinically intolerant..$^{5-7}$ Hypersensitivity to gliadin is considered to be an important aetiological feature in coeliac disease and is manifested by the presence of raised antigliadin antibody levels. However, antibodies to other dietary antigens have also been shown in coeliac disease patients without clinical evidence of intolerance. ${ }^{1021}$ Since it is postulated that both conditions share the same mucosal permeability defect, the presence of these antibodies may simply represent a secondary phenomenon. The effect of treatment on intestinal permeability is not certain. In Crohn's disease, Logan et al ${ }^{22}$ claimed that elemental diet reduces mucosal permeability, although the data of Hollander et $a l^{19}$ suggest that the permeability defect of Crohn's disease still exists in patients with quiescent disease. Jarnasson et $a l^{23}$ showed that the permeability defect in coeliac disease persists even after treatment with gluten free diet. These observations indicate that in both conditions some degree of mucosal permeability exists even when the disease is quiescent and this may therefore explain the presence of high IgG and IgA titres in patients with inactive Crohn's disease and the failure of elemental diet treatment to reduce antibody levels.

$S$ cerevisiae has not been directly implicated in the pathogenesis of Crohn's disease. The organism is a ubiquitous micro-organism that rarely causes significant human infections. The immune response observed to it described in this study may have resulted from a reaction either to antigens on the $S$ cerevisiae itself or to an as yet unidentified antigen(s) which cross reacts with $S$ cerevisiae antigens.

This work was supported by research grants from the Trustees of the former United Sheffield Hospitals and Cow \& Gate Ltd.

1 Heaton KW, Thornton JR, Emmett PM. Treatment of Crohn's disease with an unrefined carbohydrate, fibre-rich diet. BMF 1979; 2: 764-6.

2 Alun-Jones V. Comparison of total parenteral nutrition and elemental diet in induction of remission of Crohn's disease. Long-term maintenance of remission by persona
exclusion diets. Dig Dis Sci 1987; 32: 1005-15.

3 Alun-Jones V, Dickinson RJ, Workman E, Wilson AJ, Freeman AH, Hunter JO. Crohn's disease: maintenance of remission by diet. Lancet 1985; ii: 177-80.

4 Kirsner JB, Shorter RB, eds. Inflammatory bowel disease. Philadelphia: Lea \& Febiger, 1975: 81-98

5 Falchuk KR, Isselbacher KJ. Circulating antibodies to bovine albumin in ulcerative colitis and Crohn's disease. Gastroenterology 1976; 70: 5-8.

6 Knoflach P, Park BH, Cunningham R, Weiser MM, Albini B Serum antibodies to Cow's milk proteins in ulcerative colitis and Crohn's disease. Gastroenterology 1987; 92: 479-85.

7 Davidson IW, Lloyd RS, Whorwell PJ, Wright R. Antibodies to maize in patients with Crohn's disease, ulcerative colitis to maize in patients with Crohn's disease, ulcerative co

8 Van de Merwe JP, Schmitz PIM, Wensinck F. Antibodies to Eubacterium and Peptostreptococcus species and the 25-33.

9 Tabaqchali S, O'Donoghue DP, Bettelheim KA. Escherichia coli antibodies in patients with inflammatory bowel disease. Gut 1978; 19: 108-13.

10 Kenrick KG, Walker-Smith JA. Immunoglobulins and 
dietary protein antibodies in childhood coeliac disease. Gut 1970; 11: 635-40.

11 Ginsberg AL, Albert M. Treatment of patients with severe steroid-dependent Crohn's disease with nonelemental formula diet. Identification of possible etiologic dietary

factor. Dig Dis $S$ ci $1989 ; 34: 1624-8$.
12 Main J, McKenzie H, Yeaman GR, Kerr MA, Robson D, Pennington GR, et al. Antibody to Saccharomyces cerevisiae (baker's yeast) in Crohn's disease. BMF 1988, 297: $1105-6$.

13 Donaldson RM. In: Sleisenger MH, Fortran JS, eds. Gastrointestinal disease. Philadelphia: Saunders, 1989: 1327

14 Best WR, Becktel JM, Singleton JW, Kern F. Development of a Crohn's disease activity index. National Co-operative Crohn's Disease Study. Gastroenterology 1976; 70: 439-44.

15 Giaffer MH, North G, Holdsworth CD. Controlled trial of polymeric versus elemental diet in treatment of active Crohn's disease. Lancet 1990; i: 816-9.

16 Giaffer MH, Cann P, Holdsworth CD. Long term effects of elemental and exclusion diets in Crohn's disease. Aliment

17 McKenzie H, Main J, Pennington CR, Parratt D. Antibody to selected strains of Saccharomyces cerevisiae (baker's and brewer's yeast) and Candida albicans in Crohn's disease. Gut 1990; 31: 536-8.

18 Barnes RMR, Allan S, Taylor, Robinson CH, Finn R Johnson PM. Serum antibodies reactive with SaccharoJohnson PM. Serum antibo myces cerevisiae in inflammatory bowel disease: is IgA antibody a marker for Crohn's disease? Int Arch Allergy Appl

19 Hollander D, Vadheim CM, Brettholz E, Peterson GM Delhaunty T, Rotter JI. Increased intestinal permeability in patients with Crohn's disease and their relatives. A possible etiologic factor. Ann Intern Med 1986; 105: 883-

20 Cobden I, Dickinson RJ, Rothwell J, Axon ATR. Intestinal permeability assessed by excretion ratios of two molecules: results in coeliac disease. BMf 1978; 2: 1060 .

21 Ferguson A, Carswell F. Precipitins to dietary proteins in serum and upper intestinal secretions of coeliac children. BMF 1972; 1:75-7.

22 Logan FRA, Gillon J, Ferrington C, Ferguson A. Reduction of gastrointestinal protein loss by elemental diet in Crohn's of gastrointestinal protein loss by elemental diet
disease of the small bowel. Gut $1981 ; 22: 383-7$.

23 Jarnasson I, Peters TJ, Veal N. A persistent defect in intestinal permeability in coeliac disease demonstrated by ${ }^{51} \mathrm{Cr}$ labelled EDTA absorption test. L ancet 1983; ii: 323-5. 